\title{
KAJIAN PEMANENAN JENIS RAMIN DI PT DIAMON RAYA TIMBER
}

\author{
(Study of Ramin Harvesting in PT Diamon Raya Timber) \\ Oleh/By: \\ Wesman Endom
}

\begin{abstract}
This study was undertaken to evaluate targeted volume of ramin cutting in PT DRT 2003 cutting area. Evaluation was done using the formula developed by French (1883). The result shows that the allowable volume to be cut for cutting area of 2,000 ha is about 9,104.3 $\mathrm{m}^{3}$ taken from 3,672 trees. Another information from tracing of logged over area shows that the number of trees cut down ranged between 5.75-14.61 with an average of 10.18 trees, and 1.3-4.0 trees of them are ramin. Other sources show that the number of trees cut down ranged between 5.65-7.22 or in average of 6 trees/ha. This study shows that the company was trying to apply forest sustain yield principle in natural forest. However, although it is allowed to cut the trees of diameter $40 \mathrm{~cm}$ and up, for the sake of sustainability, the cutting of large diameter trees should be limited in order to provide more mother trees as sources of seed and natural seedlings in the future.
\end{abstract}

Key words: Ramin, volume, harvesting, mother trees, sustainability

\begin{abstract}
ABSTRAK
Kajian ini dilakukan untuk mengevaluasi target volume tebangan kayu ramin tahun 2003 di PT DRT. Evaluasi dilakukan menggunakan metode French (1883). Hasilnya memperlihatkan volume tebangan untuk seluas 2.000 ha sekitar $9.104,3 \mathrm{~m} 3$ berasal dari sebanyak 3.672 pohon. Dari hasil penelusuran pada lokasi bekas tebangan diketahui penebangan dilakukan antara 5,75-14,61 pohon atau rata-rata 10,18 batang; dengan sekitar 1,3 - 4,0 batang di antaranya dari jenis kayu ramin. Sumber informasi lain memperlihatkan pohon ramin yang ditebang antara 5,65 - 7,22 batang/ha atau rata-rata 6 batang/ha. Besaran ini memperlihatkan bahwa perusahaan telah berusaha menerapkan prinsip kelestarian pemanenan di hutan alam. Kendati demikian untuk menambah tingkat kelestariannya maka penebangan pohon berdiameter besar perlu dibatasi, utamanya diperlukan untuk penyediaan pohon induk yang sangat penting sebagai sumber benih dan anakan alam masa mendatang.
\end{abstract}




\section{Kata kunci: Ramin, volume, pemanenan, pohon induk , kelestarian}

\section{PENDAHULUAN}

Hutan rawa/gambut di Indonesia luasnya sekitar 13 juta hektar dengan penyebaran terutama di Sumatera, Kalimantan dan Irian Jaya (Soerianegara dan Indrawan, 1984). Kondisinya selalu basah, tak terpengaruh iklim dengan lapisan tanah berupa liat/lempung berada di bawah gambut setebal lebih dari $1 \mathrm{~m}$. Keasaman $(\mathrm{pH})$ sekitar 3,2 dengan sifat penggenangan permanen atau temporer. Dari jenis kayu hutan rawa yang memiliki nilai ekonomi itu salah satunya ialah jenis kayu ramin (Gonystilus bancanus Kurz). Jenis kayu lainnya antara lain Alstoonia, Amoora, Dryobalanop spp, Durio carinatus, Eugenia, Gonystilus, Jakia ornate, Koompasia malaccensis, Lisa, Lophopethalum. Melanorhea, Pandanus spp, Parastemon, Payena, Pholidarcapus spp, Ploaiarium, Sapotaceae div.; Shorea spp, Tetrameristica glabra, Tristania, Xylopia, dan Zalacca (Soemarna dan Sudiono, 1976)

Di hutan rawa gambut yang utuh dan mempunyai pohon induk ramin cukup, anakan alam mencapai jumlah sekitar 4.000 batang/ha dengan penyebaran tak jauh dari pohon induk/dewasa karena buahnya cukup berat (Alrasyid dan Soerianegara, 1976). Di Teluk Umpan, Kalimantan Tengah, kerapatan pohon ramin yang semula berjumlah 45 batang/ha, setahun setelah penebangan ternyata tidak ditemukan lagi (Daryono, 1996). Bahkan, jumlah permudaan tingkat pancang dan tiang di hutan alam ramin bekas tebangan di Tangkiling dan Sampit, sangat kurang (Sutisna, Soeyatman dan Wardani, 1988). Dengan masa berbuah 4 tahun sekali sedang pengayaan dengan bibit cabutan alam maupun melalui persemaian 
sering mengalami tingkat kematian yang tinggi, maka ketersediaannya sangat rawan terlebih bila penebangan dilakukan sembarangan (Alrasyid dan Soerianegara, 1976).

Menurut Partomihardjo (2006), meskipun sudah sejak lama ramin menjadi target penebangan, namun hingga kini sifat biologinya masih belum diketahui dengan baik. Pola sebaran, strategi regenerasi dan adaptasi lingkungan sehingga ramin merajai habitat gambut masih merupakan misteri yang belum terpecahkan. Berbagai kajian dan penelitian telah dilakukan, namun sejauh ini hasilnya belum mampu menjawab tantangan laju penurunan dan kemerosotan populasi ramin. Ini terbukti dari terus menurunnya populasi ramin di habitat alam dan belum ada tanda-tanda keberhasilan penanaman dalam skala yang seimbang dengan laju penurunannya.

Di Indonesia salah satu pemilik konsesi yang memiliki kekayaan alam hutan rawa jenis ramin adalah PT Diamon Raya Timber (DRT) yang berlokasi di Dumai, Propinsi Riau. Dengan mengingat sinyalemen semakin kuat dikhawatirkannya ancaman kepunahan jenis ramin di satu sisi dan pemanfaatannya yang berkelanjutan di sisi lain; maka dalam tulisan ini dicoba disajikan hasil kajian untuk mengevaluasi seberapa besar pemanenan jenis ramin di DRT yang cukup proporsional dapat dilakukan, mengingat kaedah kelestarian tersebut. Kajian dilakukan dengan menggunakan metode French dengan mengambil data potensi dari sejumlah petak tebang yang ada. 


\section{METODE KAJIAN}

\section{A. Pendekatan}

Metode yang digunakan dalam kajian ini adalah dengan metode French (1883) yang diuraikan dalam Jerram (1987), dengan formulasi sebagai berikut.

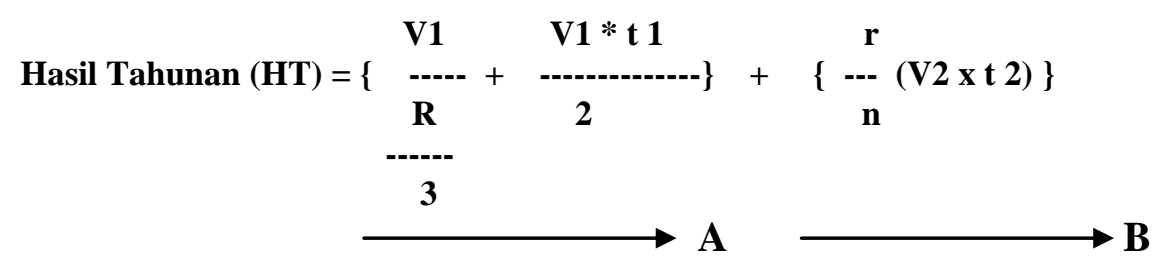

di mana: V1 = Volume kelas diameter besar; V2 = Volume kelas diameter sedang;

t 1 = riap volume kelas diameter besar; $\mathrm{t} 2$ = riap volume kelas diameter sedang; $r$ = rata-rata umur di mana diperkirakan pohon besar ditebang; dan

$\mathrm{n}$ = faktor yang bervariasi sesuai kondisi ( 1 sampai dengan 3 ).

Cara ini dipakai di hutan pegunungan oleh Huffel di Vosges atas dasar pertimbangan pemanenannya yang bersifat semi lindung alami yakni sistem penebangan konservatif dengan cara tebang pilih berdasarkan limit diameter. Proporsi pemanenan dibedakan sesuai proporsi potensi Growing Stock $(G S)$ dalam tiga kelompok yakni tua yang berdiameter besar (KDB), kelompok berdiameter sedang (KDS) dan kelompok berdiameter kecil (KDK) dengan perbandingan $5: 3: 1$. Untuk itu sebelumnya perlu dilakukan inventarisasi dan membagi kawasan ke dalam dua blok yang diperlukan untuk penyusunan rencana kegiatan kerja. Semua pohon berdiameter batang lebih dari $20 \mathrm{~cm}$ pada kedua blok dihitung dan diukur, kemudian dibagi ke dalam tiga kelas yakni : diameter besar $>40 \mathrm{~cm}(\mathrm{KDB})$, kelompok diameter sedang 20-39 cm (KDS) dan diameter kecil < 20 cm (tidak diukur). 
Rumus bagian A adalah tegakan yang harus ditebang dengan perbandingan yang sesuai dengan pertumbuhan selama $1 / 3$ periode rotasi dan kelak digantikan oleh pohon kelas diameter sedang. Rumus bagian B adalah besarnya penjarangan dari pertumbuhan pohon berdiameter sedang yang tidak diperlukan guna menggantikan pohon besar.

\section{B. Bahan dan Peralatan}

Kajian dilakukan dengan mengambil sumber data hasil kruising yang telah dilakukan perusahaan DRT pada 20 petak tebang, yaitu petak tebang nomor 771, 772, 773, 774, 803, 802, 801, 800, 838, 839, 840, 841, 867, 866, 865, 864, 902, 903, 904 dan 905.

Untuk melihat gambaran jenis dan struktur tegakan dilakukan pengamatan lapangan pada sejumlah contoh petak ukur, sedang untuk mengetahui kinerjanya dilakukan juga pengamatan terhadap tunggak tebangan di dua Tempat Pengumpulan Semantara (TPn) dengan cara mengikuti dan memetakan sekitar bekas jalur-jalur ongkak.

\section{Analisis}

Analisis dilakukan untuk mencoba mengetahui besarnya penetapan volume tebangan untuk perusahaan DRT berdasarkan metode French dalam Jerram (1987). 


\section{HASIL DAN PEMBAHASAN}

\section{A. Potensi Tegakan}

Gambaran jenis, struktur dan kerapatan pohon yang menyusun tegakan hutan rawa gambut berdasarkan kelas diameter 10-19 cm, 20-39 cm, dan $\geq 40 \mathrm{~cm}$ disajikan pada Tabel 1 .

Tabel 1. Jenis, komposisi dan struktur tegakan di hutan rawa DRT

Table 1. Tree species, composition and structure of swamp forest in DRT

\begin{tabular}{|c|c|c|c|c|c|c|c|c|c|}
\hline \multirow{3}{*}{$\begin{array}{c}\text { JENIS POHON } \\
(S P E C I E S)\end{array}$} & \multicolumn{5}{|c|}{ KELAS DIAMETER (DIAMETER CLASS) (CM) } & \multirow{2}{*}{\multicolumn{2}{|c|}{$\begin{array}{r}\text { JUMLAH } \\
(\text { TOTAL) }\end{array}$}} & \multirow{2}{*}{\multicolumn{2}{|c|}{$\%$}} \\
\hline & \multirow{2}{*}{$\begin{array}{c}10-19 \\
\mathrm{~N}\end{array}$} & \multicolumn{2}{|c|}{$20-39$} & \multicolumn{2}{|c|}{$\geq 40$} & & & & \\
\hline & & $\mathrm{N}$ & $\mathrm{V}$ & $\mathrm{N}$ & $\mathrm{V}$ & $\mathrm{N}$ & $\mathrm{V}$ & $\mathrm{N}$ & $\mathrm{V}$ \\
\hline Kayu Arang & 26.00 & 8.00 & 1.74 & 0.00 & 0.00 & 34.00 & 1.74 & 5.13 & 0.65 \\
\hline Balam & 47.00 & 24.00 & 14.79 & 2.00 & 3.15 & 73.00 & 17.94 & 11.01 & 6.71 \\
\hline Beringin & 0.00 & 2.00 & 0.36 & 0.00 & 0.00 & 2.00 & 0.36 & 0.30 & 0.13 \\
\hline Bintangur & 4.00 & 1.00 & 0.26 & 0.00 & 0.00 & 5.00 & 0.26 & 0.75 & 0.10 \\
\hline Darah-darah & 15.00 & 6.00 & 1.83 & 0.00 & 0.00 & 21.00 & 1.83 & 3.17 & 0.68 \\
\hline Durian burung & 4.00 & 1.00 & 0.88 & 6.00 & 14.82 & 11.00 & 15.70 & 1.66 & 5.87 \\
\hline Jambu-jambu & 38.00 & 28.00 & 10.00 & 1.00 & 1.24 & 67.00 & 11.24 & 10.11 & 4.21 \\
\hline Jangkang & 1.00 & 1.00 & 2.09 & 0.00 & 0.00 & 2.00 & 2.09 & 0.30 & 0.78 \\
\hline Kelat & 20.00 & 24.00 & 3.09 & 3.00 & 4.69 & 47.00 & 7.78 & 7.09 & 2.91 \\
\hline Kenari & 1.00 & 0.00 & 0.00 & 0.00 & 0.00 & 1.00 & 0.00 & 0.15 & 0.00 \\
\hline Kopi-kopi & 1.00 & 0.00 & 0.00 & 0.00 & 0.00 & 1.00 & 0.00 & 0.15 & 0.00 \\
\hline Malam-malam & 2.00 & 3.00 & 1.35 & 1.00 & 1.64 & 6.00 & 2.99 & 0.90 & 1.12 \\
\hline Mangga & 19.00 & 12.00 & 5.85 & 0.00 & 0.00 & 31.00 & 5.85 & 4.68 & 2.19 \\
\hline Manggis & 5.00 & 3.00 & 2.09 & 0.00 & 0.00 & 8.00 & 2.09 & 1.21 & 0.78 \\
\hline Medang lendir & 3.00 & 6.00 & 4.14 & 0.00 & 0.00 & 9.00 & 4.14 & 1.36 & 1.55 \\
\hline Medang telor & 15.00 & 2.00 & 0.48 & 0.00 & 0.00 & 17.00 & 0.48 & 2.56 & 0.18 \\
\hline Medang & 6.00 & 2.00 & 0.56 & 0.00 & 0.00 & 8.00 & 0.56 & 1.21 & 0.21 \\
\hline Mangkal udang & 2.00 & 0.00 & 0.00 & 0.00 & 0.00 & 2.00 & 0.00 & 0.30 & 0.00 \\
\hline Milas & 10.00 & 23.00 & 19.55 & 2.00 & 1.88 & 35.00 & 21.43 & 5.28 & 8.02 \\
\hline Meranti batu & 16.00 & 10.00 & 7.00 & 6.00 & 21.46 & 32.00 & 28.46 & 4.83 & 10.65 \\
\hline Meranti bunga & 3.00 & 7.00 & 6.18 & 4.00 & 15.80 & 14.00 & 21.99 & 2.11 & 8.23 \\
\hline Nangka-nangka & 29.00 & 3.00 & 1.10 & 0.00 & 0.00 & 32.00 & 1.10 & 4.83 & 0.41 \\
\hline Nyatoh & 1.00 & 6.00 & 3.95 & 2.00 & 0.00 & 9.00 & 3.95 & 1.36 & 1.48 \\
\hline Pasir-pasir & 48.00 & 9.00 & 5.06 & 0.00 & 0.00 & 57.00 & 5.06 & 8.60 & 1.89 \\
\hline Pisang-pisang & 7.00 & 7.00 & 5.32 & 4.00 & 12.37 & 18.00 & 17.69 & 2.71 & 6.62 \\
\hline Pasak lingau & 1.00 & 1.00 & 0.36 & 1.00 & 2.60 & 3.00 & 2.96 & 0.45 & 1.11 \\
\hline Pulai & 1.00 & 1.00 & 1.25 & 1.00 & 1.45 & 3.00 & 2.71 & 0.45 & 1.01 \\
\hline Punak & 4.00 & 2.00 & 1.46 & 7.00 & 12.94 & 13.00 & 14.40 & 1.96 & 5.39 \\
\hline Ramin & 5.00 & 4.00 & 1.68 & 7.00 & 21.34 & 16.00 & 23.02 & 2.41 & 8.61 \\
\hline Resak & 0.00 & 2.00 & 0.76 & 0.00 & 0.00 & 2.00 & 0.76 & 0.30 & 0.28 \\
\hline
\end{tabular}




\begin{tabular}{|c|c|c|c|c|c|c|c|c|c|}
\hline Sentul & 1.00 & 1.00 & 0.35 & 0.00 & 0.00 & 2.00 & 0.35 & 0.30 & 0.13 \\
\hline Suntai & 9.00 & 11.00 & 5.83 & 13.00 & 35.18 & 33.00 & 41.01 & 4.98 & 15.34 \\
\hline Terentang & $\mathbf{9 . 0 0}$ & $\mathbf{1 1 . 0 0}$ & $\mathbf{4 . 7 6}$ & $\mathbf{1 . 0 0}$ & $\mathbf{2 . 6 1}$ & $\mathbf{2 1 . 0 0}$ & $\mathbf{7 . 3 7}$ & $\mathbf{3 . 1 7}$ & $\mathbf{2 . 7 6}$ \\
\hline Terpis & 4.00 & 0.00 & 0.00 & 0.00 & 0.00 & 4.00 & 0.00 & 0.60 & 0.00 \\
\hline Timah-timah & 22.00 & 0.00 & 0.00 & 0.00 & 0.00 & 22.00 & 0.00 & 3.32 & 0.00 \\
\hline Xanthophlyum & 2.00 & 0.00 & 0.00 & 0.00 & 0.00 & 2.00 & 0.00 & 0.30 & 0.00 \\
\hline TOTAL & 381.00 & 221.00 & 114.13 & 61.00 & 153.16 & 663.00 & 267.29 & 100.00 & 100.00 \\
\hline
\end{tabular}

Catatan/Note: Yang diketik tebal ditebang perusahaan/Bold typed is cut by company

$\mathrm{N}=$ jumlah batang /Number of tree; $V=m^{3} / h a$

Sumber/Source : Hasil kruising DRT/Timber cruising of DRT

Dari Tabel 1 dapat dilihat ada 35 jenis pohon yang tumbuh di alam. Dari sejumlah itu, yang diambil atau ditebang oleh perusahaan ada 11 jenis pohon (30\%). Bagi jenis ramin sendiri, proporsi kerapatannya terhadap jenis-jenis lainnya relatif kecil yakni di bawah 3\% untuk jumlah batang dan sekitar $8 \%$ terhadap volume total. Kecilnya kerapatan pohon tersebut mengindikasikan bahwa memang perlu dilakukan kehati-hatian dalam melasanakan pemanfaatannya dari tegakan alam, karena apabila diambil secara sembarangan, maka pengganti atau penerusnya akan menjadi lebih kecil peluang keberadaannya di alam. Terlebih permudaan untuk tingkat pancang dan tiang juga jarang sehingga bila terjadi kerusakan tegakan baik karena akibat kegiatan penebangan atau akibat pembuatan jalan ongkak, atau jalan rel, dikhawatirkan akan dapat mengganggu kesinambungannya. Cukup kecilnya kerapatan tegakan jenis ramin tersebut dapat dilihat dari pembandingnya seperti berikut.

Tabel 2. Rata-rata jumlah pohon dan volume pohon jenis komersial dan jenis ramin per ha hasil pengamatan di petak permanen PT Diamon Raya Timber.

Table 2. The average number and volume of commercial tree species and ramin per ha collected from permanent plot at PT Diamon Raya Timber.

\begin{tabular}{|c|c|c|c|c|c|c|}
\hline \multirow{3}{*}{$\begin{array}{l}\text { Kelompok } \\
\text { Jenis/Group of species }\end{array}$} & \multicolumn{6}{|c|}{$\begin{array}{l}\text { Jumlah pohon (batang) dan Volume }\left(\mathrm{m}^{3}\right) \text { per ha per kelas diameter } \\
\text { Number of tree (pieces) and volume }\left(\mathrm{m}^{3}\right) \text { per ha per diameter class }\end{array}$} \\
\hline & $10-19$ & & $20-39$ & & 40 up & \\
\hline & $\mathrm{N}$ & $\mathrm{V}$ & $\mathrm{N}$ & $\mathrm{V}$ & $\mathrm{N}$ & $\mathrm{V}$ \\
\hline Kome & 17.90 & 2.16 & 67.90 & 44.97 & 37.96 & 100.85 \\
\hline Ramin & 1.85 & 0.26 & 4.01 & 3.32 & 5.87 & 18.94 \\
\hline
\end{tabular}


Sumber /Source : Istomo (2006).

Tabel 3. Rata-rata potensi kayu saat ini dari jenis ramin di Riau dan Jambi

Table 3. Average of current potency of ramin in Riau and Jambi

\begin{tabular}{|l|c|c|c|c|}
\hline \multirow{2}{*}{$\begin{array}{l}\text { Propinsi/Konsesi } \\
\text { (Province/Concesssion area) }\end{array}$} & \multicolumn{4}{|c|}{ Diameter } \\
\cline { 2 - 5 } & $\mathrm{N}$ & $\mathrm{V}$ & $\mathrm{N}$ & $\mathrm{V}$ \\
\cline { 2 - 5 } & 1.22 & 0.81 & 4.48 & 12.96 \\
\hline Riau (PT Diamon Raya Timber) & 1.46 & 1.01 & 0.44 & 0.95 \\
\hline Jambi (PT Putra Duta Indah Wood) & 1.49 & \\
\hline
\end{tabular}

Keterangan (Remark) $: \mathrm{N}=$ jumlah pohon per ha /Number of trees per ha $\mathrm{V}=$ volume, $\mathrm{m}^{3} / \mathrm{ha}$

Sumber (Source): Bismark $\underline{\text { et }} \underline{\text { al }}$ (2006)

Dari Tabel 2 dan Tabel 3 dapat dilihat bahwa kerapatan jenis ramin tidak mencapai 7 batang per ha khususnya untuk kelompok diameter $40 \mathrm{~cm}$ ke atas. Demikian juga untuk kelompok diameter 20-39 $\mathrm{cm}$ dan kelompok diameter 10-19 $\mathrm{cm}$. Kekhawatiran di atas semakin besar karena maraknya kegiatan penebangan liar maupun konversi lahan menjadi perkebunan kelapa sawit.

\section{B. Penetapan Volume Tebangan}

Mengingat karakteristik alami jenis ramin sebagaimana telah disebutkan di atas, maka persyaratan kelestarian merupakan pertimbangan yang harus diutamakan dalam pemanfaatannya. Kaidah ini sejak awal harus diperhatikan dan untuk itu maka potensinya harus sudah dapat diidentifikasi agar dapat dibuat rencana pemanfaatannya dengan baik dan proporsional. Hal ini mutlak diperlukan dengan pengertian agar tidak selalu menebang pohon berdiameter $40 \mathrm{~cm}$ ke atas, sekalipun ketentuan yang berlaku membolehkannya. Pembatasan ini dinilai penting dengan tujuan agar masih terdapat sejumlah pohon besar sebagai sumber benih. Apalagi sebagaimana diketahui bahwa di samping buahnya cepat 
membusuk (rekalsitran), juga karena waktu pembungaan jenis ramin lambat yaitu hanya berlangsung 4 tahun sekali (Alrasyid dan Soerianegara, 1976).

Dalam kajian ini potensi jenis kayu ramin dicoba dilihat dari sejumlah petak tebang dengan melihat kondisinya yang dikelompokkan dalam potensi normal dan potensi aktual. Potensi normal yaitu potensi yang disepadankan dengan kondisi ideal sesuai dengan keadaan potensi di sekitar petak-petak tersebut. Penetapannya dilakukan dengan cara melihat dari peta foto tutupan lahan hutan yang tersedia di perusahaan. Besar potensi didasarkan pada informasi potensi yang dinampakkan oleh model tutupan hutan sejenis di sekitarnya. Sedang potensi aktual adalah potensi yang diperoleh dari hasil pengukuran lapangan. Dari upaya ini dapat diperoleh gambaran dari sejumlah petak tebang yang keadaan potensinya sebagai berikut.

Table 3. Potensi aktual dan potensi normal serta selisih potensi pada RKT 2003 Table 3. Actual and normal potential of forest stand of ramin species on RKT 2003

\begin{tabular}{|c|c|c|c|c|c|c|c|c|c|c|c|}
\hline \multirow{2}{*}{$\begin{array}{c}\text { Kelas } \\
\text { Diameter/ } \\
\text { Diameter } \\
\text { class }\end{array}$} & \multirow{2}{*}{$\begin{array}{l}\text { Petak } \\
\text { tebang/ } \\
\text { Cutting } \\
\text { block }\end{array}$} & \multicolumn{2}{|c|}{$\begin{array}{l}\text { Potensi normal/ } \\
\text { Normal volume }\end{array}$} & \multicolumn{2}{|c|}{$\begin{array}{l}\text { Potensi aktual/ } \\
\text { Actual volume }\end{array}$} & \multicolumn{2}{|c|}{+} & \multicolumn{2}{|c|}{ - } & \multicolumn{2}{|c|}{$\begin{array}{c}\text { Selisih/ } \\
\text { Difference }\end{array}$} \\
\hline & & $\mathrm{N}$ & $\mathrm{V}$ & $\mathrm{N}$ & $\mathrm{V}$ & $\mathrm{N}$ & $\mathrm{V}$ & $\mathrm{N}$ & $\mathrm{V}$ & $\mathrm{N}$ & $\mathrm{V}$ \\
\hline KDB & 771 & 800 & 2.300 & 818 & $2.327,97$ & 18 & 27,97 & & & & \\
\hline & 772 & 200 & 500 & 200 & 500,00 & 0 & 0 & & & & \\
\hline & 773 & 100 & 290 & 150 & 375,00 & 50 & 85 & & & & \\
\hline & 774 & 100 & 250 & 100 & 250,00 & $\underline{0}$ & 0 & & & & \\
\hline & 803 & 700 & 2.125 & 719 & $2.171,93$ & 19 & 46,93 & & & & \\
\hline & 802 & 300 & 780 & 350 & 875,00 & 50 & 95 & & & & \\
\hline & 801 & 155 & 390 & 150 & 375,00 & & & -5 & -15 & & \\
\hline & 800 & 100 & 250 & 100 & 250,00 & 0 & 0 & & & & \\
\hline & 838 & 100 & 300 & 75 & 267,07 & & & -25 & $-32,93$ & & \\
\hline & 839 & 200 & 525 & 200 & 525,00 & 0 & 0 & & & & \\
\hline & 840 & 150 & 375 & 150 & 375,00 & $\underline{0}$ & 0 & & & & \\
\hline & 841 & 100 & 225 & 100 & 250,00 & 12 & 25 & & & & \\
\hline & 867 & 250 & 675 & 241 & 647,02 & & & -9 & $-27,98$ & & \\
\hline & 866 & 100 & 325 & 75 & 267,66 & & & -25 & $-57,34$ & & \\
\hline & 865 & 150 & 225 & 150 & 225,00 & 0 & 0 & & & & \\
\hline & 864 & 100 & 150 & 100 & 150,00 & 0 & 0 & & & & \\
\hline & 902 & 250 & 675 & 252 & 678,91 & 2 & 3,91 & & & & \\
\hline & 903 & 200 & 500 & 200 & 500,00 & 0 & 0 & & & & \\
\hline & 904 & 100 & 300 & 75 & 267,91 & & & -25 & $-32,09$ & & \\
\hline & 905 & 100 & 300 & 75 & 267,66 & & & -25 & $-32,34$ & & \\
\hline
\end{tabular}




\begin{tabular}{|l|l|l|l|l|r|r|r|r|r|l|l|}
\hline $\begin{array}{l}\text { Jumlah/ } \\
\text { Total }\end{array}$ & & & 11.985 & & $11.545,13$ & 151 & 283,81 & -114 & $-197,68$ & 37 & 86,13 \\
\hline & & & & & & & & & & & \\
\hline & & & & & & & & & & & \\
\hline KDS & & & & & & & & & & & \\
\hline & 771 & 500 & 475,0 & 457 & 430,15 & & & -43 & $-44,85$ & & \\
\hline & 773 & 400 & 380,0 & 400 & 380,00 & 0 & 0 & & & & \\
\hline & 774 & 250 & 237,5 & 300 & 285,00 & 50 & 47,5 & & & & \\
\hline & 803 & 200 & 190,0 & 213 & 194,59 & 13 & 14,59 & & & & \\
\hline & 802 & 300 & 285,0 & 300 & 285,00 & 0 & 0 & & & & \\
\hline & 801 & 250 & 237,5 & 250 & 237,50 & 0 & 0 & & & & \\
\hline & 800 & 150 & 142,5 & 200 & 190,00 & 50 & 47,5 & & & & \\
\hline & 838 & 200 & 190,0 & 66 & 76,78 & & & -134 & $-113,22$ & & \\
\hline & 839 & 200 & 190,0 & 200 & 190,00 & 0 & 0 & & & & \\
\hline & 840 & 150 & 142,5 & 150 & 142,50 & 0 & 0 & & & & \\
\hline & 841 & 100 & 95,0 & 100 & 95,00 & 0 & 0 & & & & \\
\hline & 867 & 250 & 190,0 & 250 & 190,00 & 0 & 0 & & & & \\
\hline & 866 & 150 & 142,5 & 69 & 60,67 & & & -81 & $-81,83$ & & \\
\hline & 865 & 140 & 135,5 & 150 & 142,50 & 10 & 7,5 & & & & \\
\hline & 864 & 100 & 95,0 & 100 & 95,00 & 0 & 0 & & & & \\
\hline & 902 & 150 & 142,5 & 82 & 77,01 & & & -68 & $-65,49$ & & \\
\hline & 903 & 100 & 95,0 & 100 & 95,00 & 0 & 0 & & & & \\
\hline & 904 & 100 & 95,0 & 66 & 60,67 & & & -34 & $-34,33$ & & \\
\hline & 905 & 100 & 90,0 & 66 & 60,67 & & & -34 & $-29,33$ & & \\
\hline & & 800 & 2.300 & & $3.525,54$ & 123 & 117,09 & -394 & $-369,05$ & -271 & $-251,96$ \\
\hline
\end{tabular}

Dengan memperhatikan pertimbangan di atas dan kemudian juga melihat praktek dan kondisi potensi tahun sebelumnya, maka untuk tahun RKT 2003 dengan luas tebangan 2000 ha, dicoba ditetapkan besarnya volume tebangan dan jumlah pohon sesuai metode French (1983) dengan cara mengelompokkan kayu ke dalam kelompok berdiameter besar (KDB) dan kelompok berdiameter sedang (KDS).

Kelompok diameter besar (KDB) adalah pohon-pohon berdiameter $40 \mathrm{~cm}$ dan ke atas dan kelompok diameter sedang (KDS) adalah pohon-pohon berdiameter 30-39 cm. Berdasarkan pengelompokkan tersebut kemudian dilakukan penghitungan sebagai berikut.

\section{- Volume}

$\begin{array}{lcccc} & \text { Potensi aktual } & \text { Potensi normal } & + & - \\ \text { KDB } & 11.545,13 & 11.985,00 & - & 439,87 \\ \text { KDS } & 3.525,54 & 3.777,50 & - & 251,96 \\ & ------------- & --- \\ & 15.070,67 & 15.762,50 & & \end{array}$




\section{- Jumlah pohon}

$\begin{array}{lcccc} & \text { Potensi aktual } & \text { Potensi normal } & + & - \\ \text { KDB } & 4.292 & 4.255 & 37 & - \\ \text { KDS } & 3.769 & 4.040 & - & 271 \\ & -------------- & ---1\end{array}$

Terlihat bahwa hutan terdapat dalam kondisi kurang normal, yang dapat dilihat dengan lebih kecilnya volume aktual dibandingkan dengan volume normal, baik pada KDB maupun KDS untuk jumlah pohon maupun volume. Pada kondisi ini diperlukan metode transfer yaitu mengganti pertumbuhan KDB oleh sekitar $46 \%$ dari KDS per tahun sedangkan $\mathrm{n}$ yang diterapkan menggunakan angka 3 untuk perhitungan itu. Penetapan batas tebangan diperoleh dengan hasil sebagai berikut:

$$
\begin{array}{rl}
\mathrm{KDB} & \mathrm{KDS} \\
\mathrm{HT} & =\{11.545,13 / 13+(11.545,13 * 0.0075) / 2\}+\{1 / 2 *(3.525,54 \times 0.025)\} \\
& =975,5 \mathrm{~m} 3
\end{array}
$$

Untuk luas tebangan 2.000 ha sedang luas arealnya sendiri 80.000 ha, maka HT akan menjadi $(80.000 / 2.000) / 3 * 975,5 \mathrm{~m} 3=13.006 \mathrm{~m}^{3}$. Untuk jumlah pohonnya dapat dihitung:

\section{KDB $\quad$ KDS}

$$
\begin{aligned}
\mathrm{PT} & =\{4292 / 13+(4292 * 0.0075) / 2\}+\{1 / 2 *(3769 \times 0.025)\} \\
& =393,1 \text { pohon }
\end{aligned}
$$

Dengan cara yang sama, karena perhitungan berasal dari luasan 2.000 ha sedang luas arealnya sendiri 80.000 ha, maka Pohon Tebang (PT) akan menjadi $(80.000 / 2000) / 3 * 393,1$ pohon $=5.244,82$ pohon. 
Bila hasil perhitungan formula itu dibandingkan dengan formula lain menggunakan perumusan Simmon (dalam Jeram, 1987) yang penebangan diambil dari 1/3 rotasi, dengan volume menjadi $x=r / 3$; maka

$$
\begin{aligned}
& \mathrm{HT}=2 \mathrm{G} / \mathrm{r}=9 \mathrm{~V} / 4 \mathrm{r} \\
& \mathrm{HT}=9(\text { volume inventory GS }) / 4 \mathrm{r}=(9 * 15070,6) /(4 * 40)=847,7 \mathrm{~m}^{3}
\end{aligned}
$$

Untuk luas tebangan 2.000 ha dari luas total 80.000 ha, maka Hasil Tahunan (HT) akan menjadi $(80.000 / 2000) / 3 * 847,7 \mathrm{~m}^{3}=11.303 \mathrm{~m}^{3}$ dengan jumlah pohonnya sebanyak 6.045 batang.

Perbandingan hasil perhitungan antara metode French dan metode Simmon menunjukkan adanya perbedaan. Kedua pendekatan tersebut menghasilkan angka volume tebangan sebesar $13.006 \mathrm{~m} 3$ untuk metode French dan sekitar 11.303 untuk metode Simmon. Dengan demikian berarti masih ada selisih sekitar $1.700 \mathrm{~m}^{3}$ atau $13 \%$. Namun perbedaan ini dapat dimaklumi karena adanya perbedaan dalam pendekatan formulasi yang dipakai, di mana pada metode French dilakukan pemisahan antara kelas diameter, sedangkan pada metode Simmon tidak dilakukan pemisahan menurut diameter. Aspek kelestarian tegakan pada metode French memerlukan pengamanan; sehingga dipandang perlu digunakan besaran pengaman bagi kelanjutan usaha, yang dalam tulisan ini diajukan sebesar 30\%. Besarnya volume tebangan yang diusulkan itu adalah $0,7 \times 13.006 \mathrm{~m}^{3}=9.104$ $\mathrm{m}^{3}$. Bila konsep ini dapat diterapkan, maka potensi tegakan ramin khususnya untuk pohon berdiameter besar masih tersedia, sehingga tersedia sumber benih secara memadai. 


\section{Realisasi Penebangan dan Produksi Ramin}

Hasil penelusuran dari jalur ongkak pada 2 TPn seluas kurang lebih 4 ha dan 2 ha dan masing-masing memiliki satu pelabuhan kayu (Beko) disajikan pada Tabel 4.

Table 4. Jumlah dan jenis pohon tebang hasil penelusuran pada alur ongkak

Table 4. Number and species cut resulted from manual skidding track tracing

\begin{tabular}{|c|c|l|c|c|c|c|c|}
\hline $\begin{array}{l}\text { TPn/ } \\
\text { Logyard }\end{array}$ & $\begin{array}{l}\text { Jumlah } \\
\text { beto/ } \\
\text { Number } \\
\text { of beto }\end{array}$ & $\begin{array}{l}\text { Jenis kayu / } \\
\text { Species }\end{array}$ & $\begin{array}{l}\text { Diameter } \\
\text { tunggak/ } \\
\text { Diameter } \\
\text { of stump }\end{array}$ & $\begin{array}{l}\text { Jumlah/ } \\
\text { Total }\end{array}$ & $\begin{array}{l}\text { Luas/ } \\
\text { Area }\end{array}$ & $\begin{array}{l}\text { Rata2/ha/ } \\
\text { (Mean/ha) })\end{array}$ & $\begin{array}{l}\text { Jumlah } \\
\text { Total }\end{array}$ \\
\hline I & 4 & Ramin & $44-66$ & 16 & 4 & 4,0 & \\
\hline & & Meranti & $42-75$ & 5 & & 1,25 & \\
\hline II & 2 & Geronggang & $48-51$ & 2 & & 0.5 & 5,75 \\
\hline & & Ramin & $43-59$ & 4 & 1,3 & 3,07 & \\
\hline & & Meranti & $44-53$ & 3 & & 2,30 & \\
\hline & & Serapat & 59 & 1 & & 0,77 & \\
\hline & & Meranti batu & $44-60$ & 5 & & 3,86 & \\
\hline & & Geronggang & $55-60$ & 2 & & 1,54 & \\
\hline & & Balam & 45 & 3 & & 2,30 & \\
\hline Rata2/Mean & & & & & & & 10,18 \\
\hline
\end{tabular}

Tabel 4 memperlihatkan rata-rata setiap hektar dilakukan penebangan antara 5,75-

14,61 pohon atau rata-rata 10,18 batang; dengan sekitar 1,3-4,0 batang di antaranya dari jenis kayu ramin. Gambaran penebangan tahun sebelumnya disajikan pada Tabel 5.

Table 5. Realisasi tebangan pohon ramin pada lima tahun terakhir Table 5. Ramin tree harvested for the last five years

\begin{tabular}{|c|c|c|c|c|c|}
\hline $\begin{array}{c}\text { Tahun RKT/ } \\
\text { Year of RKT }\end{array}$ & $\begin{array}{c}\text { Luas/ } \\
\text { Area } \\
(\text { ha })\end{array}$ & $\begin{array}{c}\text { Pohon/ } \\
\text { Tree }\end{array}$ & $\begin{array}{c}\text { Batang/ } \\
\text { Logs }\end{array}$ & Volume & $\begin{array}{c}\text { Rata2 pohon/ha/ } \\
\text { Mean tree/ ha }\end{array}$ \\
\hline $1997 / 1998$ & 1869,00 & 10.564 & 39.615 & $29.875,5$ & 5,65 \\
\hline $1998 / 1999$ & 1901,00 & 13.728 & 51.481 & $34.217,24$ & 7.22 \\
\hline $1999 / 2000$ & 460,00 & 3.013 & 11.299 & $8.304,61$ & 6.55 \\
\hline 2000 & 993,42 & 6.730 & 25.239 & $17.281,91$ & 6.77 \\
\hline 2001 & 1694,87 & 11.566 & 43.273 & $28.369,41$ & 6.82 \\
\hline $\begin{array}{c}\text { Tahun berjalan 2002/ } \\
\text { (Year of 2002) }\end{array}$ & 268,69 & 1.730 & 6.147 & $4.358,36$ & 6.44 \\
\hline
\end{tabular}

Sumber (Source) : Partomihardjo (2005). 
Dari Tabel 5 dapat dilihat bahwa banyaknya pohon ramin yang ditebang berkisar antara 5,65 - 7,22 pohon/ha atau rata-rata 6 pohon/ha. Dari gambaran ini cukup jelas bahwa pada masa sebelum diberlakukannya CITES perusahaan telah melakukan penebangan secara hati-hati yang berarti perusahaan telah berusaha untuk menerapkan prinsip kelestarian pemanenan di hutan alam.

\section{Upaya Pengusahaan Kelestarian Jenis Ramin}

\section{Penyediaan pohon induk sumber benih}

Hasil pengamatan lapangan menunjukkan perusahaan telah melakukan penunjukkan sejumlah pohon induk berdiameter $>40 \mathrm{~cm}$ pada setiap petak tebang sesuai yang disarankan. Dengan demikian tersedia pohon induk sebagai sumber benih dan anakan alam ramin untuk siklus tebang yang akan datang.

\section{Penanaman pengayaan}

Untuk penanaman sebaiknya dilakukan pada saat air rawa surut yaitu pada akhir musim kemarau (Dien dan Kartiko, 2001). Namun beberapa hal penting yang perlu diperhatikan agar upaya ini dapat berhasil: (a) pada saat muda diperlukan naungan berat (sampai 90\% dari sinar matahari langsung); (b) kondisi alamnya tidak merobah tipe hutan rawa gambut dan (c) melakukan pengayaan buatan dengan cara penggenangan yang teratur.

\section{Pembuatan persemaian ramin}

Persemaian ramin yang berasal dari stek pucuk sudah dimulai dan beberapa di antaranya sudah menunjukkan tanda-tanda pertumbuhan. Agar persemaian lebih baik perlu dibuat lebih permanen diikuti dengan percobaan penanaman ramin agar kesulitan mendapatkan bibit dapat terantisipasi. 


\section{KESIMPULAN DAN SARAN}

Berdasarkan kajian dapat diambil beberapa kesimpulan dan saran sebagai berikut.

1. Potensi ramin di alam sangat bervariasi dengan kecenderungan semakin mendekat ke arah laut semakin menurun potensinya.

2. Di konsesi hutan rawa gambut DRT, terdapat 35 jenis pohon yang dari sejumlah itu 11 jenis pohon $(30 \%)$ ditebang oleh perusahaan. Jenis ramin sendiri, proporsi kerapatan terhadap jenis-jenis lainnya relatif kecil yakni di bawah 3\% untuk jumlah batang dan sekitar $8 \%$ terhadap volume total. Untuk kelompok diameter $40 \mathrm{~cm}$ ke atas kerapatan jenis ramin tidak mencapai 7 batang/ha. Demikian juga untuk kelompok diameter 20$39 \mathrm{~cm}$ dan kelompok diameter 10-19 $\mathrm{cm}$. Besaran ini mengindikasikan perlunya melasanakan pemanfaatannya secara hati-hati.

3. Kajian dengan menggunakan metode French mendapatkan besarnya volume tebangan jenis ramin sekitar 9.104,3 m3 yang berasal dari sebanyak 3.672 pohon. Kendati demikian, perlu ditambahkan faktor pengaman tegakan sebesar 30\% terhadap sejumlah pohon tebang, dalam arti agar tidak selalu menebang pohon berdiameter $40 \mathrm{~cm}$ ke atas sekalipun ketentuan yang berlaku membolehkannya. Ini diperlukan utamanya untuk penyediaan pohon induk yang sangat penting sebagai sumber benih dan anakan alam masa mendatang. Di sisi lain rasa kekhawatiran akan punahnya jenis ramin sangat nyata karena maraknya kegiatan penebangan liar maupun konversi lahan hutan rawa menjadi perkebunan kelapa sawit.

4. Ada perbedaan hasil perhitungan besarnya volume tebangan antara metode French dan Simmon. Perbedaan terjadi karena adanya perbedaan dalam pendekatan formulasi yang dipakai. 
5. Hasil penelusuran pada lokasi bekas tebangan memperlihatkan pohon yang ditebang antara 5,75-14,61 pohon atau rata-rata 10,18 batang; dengan sekitar 1,3-4,0 batang di antaranya dari jenis kayu ramin. Sumber data lain memperlihatkan bahwa banyaknya pohon ramin yang ditebang berkisar antara 5,65 sampai 7,22 batang pohon per hektar atau rata-rata 6 batang pohon per hektar. Gambaran ini memperlihatkan bahwa perusahaan telah berusaha untuk menerapkan prinsip kelestarian pemanenan di hutan alam.

6. Pengayaan hutan dan persemaian perlu lebih dikembangkan lebih intensif dan terus menerus dilakukan percobaan penanamannya untuk mengantisipasi kendala yang terjadi.

\section{DAFTAR PUSTAKA}

AlRasyid, H. dan I. Soerianegara. 1976. Pedoman sementara penanaman kayu ramin (Gonystylus bancanus Kurz). Laporan No 231. Lembaga Penelitian Hutan. Bogor.

Bismark, M; A. Wibowo; T. Kalima and R. Sawitri. 2006. Current growing stock of Ramin in Indonesia. Prosiding seminar Konservasi dan Pembangunan Hutan Ramin di Indonesia tanggal 22 Februari di Bogor. Pusat Litbang Hutan dan Konservasi Alam. Bogor.

Daryono, H. 1996. Kondisi tegakan tinggal dan permudaan alam hutan rawa gambut setelah pembalakan dan teknik propagasinya. Makalah pada Diskusi Hasil Penelitian dalam Menunjang Pemanfaatan Hutan yang Lestari, tanggal 11-12 Maret 1996 di Bogor. Pusat Penelitian dan Pengembangan Hutan dan Konservasi Alam. Bogor.

Dien, H. dan P. Kartiko. 2001. Budidaya tanaman langka bernilai ekonomi tinggi : Ramin. Duta Rimba 25 (254) : 36-39. Perum Perhutani. Jakarta.

Endom, W. 2002. Gambaran cuplikan sebaran pertumbuhan alami jenis ramin di hutan rawa gambut HPH PT Diamon Raya Timber dalam kaitan dengan upaya pemanfaatannya secara lestari. Naskah. Tidak diterbitkan.

Istomo; I. Soerianegara, E. Suhendang, dan S. Sabiham. 1994. Hubungan antara komposisi, struktur dan penyebaran ramin (Gonystylus bancanus (Miq) (Kurz.) dengan sifat-sifat tanah gambut (Studi kasus di areal HPH PT Inhutani III, Kalimantan Tengah. Laboratorium Ekologi Hutan, Fakultas Kehutanan IPB. Bogor. 
Istomo. 2006. Evaluasi dan penyesuaian praktek/sistem silvikultur hutan rawa gambut di Indonesia khususnya untuk jenis ramin. Prosiding seminar Konservasi dan Pembangunan Hutan Ramin di Indonesia tanggal 22 Februari di Bogor. Pusat Litbang Hutan dan Konservasi Alam. Bogor.

Jerram, M.R.K. 1987. A text Book on Forest Management. Periodical Expert Book Agency D-42 Viviek Vihar, Delhi -110032. India.

Partomihardjo, T. 2005. Potret pohon ramin (Gonystylus banqanus) di Pulau Sumatera dan ancaman kepunahan. Prosiding seminar Konservasi dan Pembangunan Hutan Ramin di Indonesia tanggal 22 Februari di Bogor. Pusat Litbang Hutan dan Konservasi Alam. Bogor.

Soemarna K. dan Y. Sudiono. 1976. Inventarisasi Hutan. Bagian Nilai Hutan, Lembaga Penelitian Hutan. Bogor.

Soerianegara, I dan A. Indrawan. 1978. Ekologi Hutan Indonesia. Departemen Manajemen Hutan Fakultas Kehutanan IPB. Bogor.

Sutisna, U ; H.C. Soeyatman dan M. Wardani. 1988. Analisis komposisi jenis pohon hutan rawa gambut Tangkilang dan Sampit, Kalimantan Tengah. Buletin Penelitian Hutan No 497 : 41-56. Pusat Penelitian dan Pengembangan Hutan dan Konservasi Alam. Bogor. 


\section{ABSTRAK \\ UDC (OSDC)B. \\ Endom, Wesman (Pusat Litbang Hasil Hutan). KAJIAN PEMANENAN JENIS RAMIN PADA KONSESI PT DIAMON RAYA TIMBER}

Kajian ini dilakukan untuk mengevaluasi target volume tebangan kayu Ramin tahun 2003 di PT DRT dengan menggunakan metode French (1883). Hasilnya memperlihatkan volume tebangan untuk seluas 2.000 ha sekitar $9.104,3 \mathrm{~m}^{3}$ berasal dari 3.672 pohon. Dari penelusuran di lokasi bekas tebangan diketahui tunggak tebangan per hektar antara 5,75-14,61 atau rata-rata 10,18 pohon dengan sekitar 1,3-4,0 dari jenis kayu ramin dan dari informasi lain menyebutkan antara 5,65 - 7,22 pohon/ha atau rata-rata 6 pohon/ha. Besaran ini memperlihatkan perusahaan telah berusaha menerapkan prinsip kelestarian di hutan alam.

Kata kunci: Ramin, volume, pemanenan, pohon induk dan kelestarian

\section{ABSTRACT}

$U D C(O S D C) B$

Endom, Wesman (Centre for Forest Products Research and Development). (Study of ramin harvesting in PT Diamon Raya Timber)

This study was undertaken to evaluate targeted volume of ramin cutting in PT DRT 2003 cutting area. Evaluation was done using the formula developed by French (1883). The result shows that the allowable volume for cutting area of 2,000 ha is about 9,104.3 $\mathrm{m}^{3}$ taken from 3,672 trees. From tracing of logged over area, it is found that the number of trees cut down ranged between 5.75-14.61 with an average of 10.18 trees, and 1.3-4.0 trees of them are ramin; and other sources showed the figure ranged between 5.65-7.22 with an average of 6 trees/ha. These figures show that the company has applied the principle of forest sustainability in their forest concession.

Key words: Ramin, volume, harvesting, mother trees and sustainability 